A concorrência desleal no direito japonês: lições para o Brasil

$$
\text { Dissertação de Mestrado }
$$

Orientador: Professor Doutor Masato Ninomiya

UNIVERSIDADE DE SÃO PAULO

FACULDADE DE DIREITO

São Paulo-SP

2018 


\section{DANILO YOSHIAKI FUJITA}

A concorrência desleal no direito japonês: lições para o Brasil

Dissertação apresentada à Banca Examinadora do Programa de PósGraduação em Direito, da Faculdade de Direito da Universidade de São Paulo, como exigência parcial para a obtenção do título de Mestre em Direito, na área de concentração Direito Internacional, sob a orientação do Prof. Dr. Masato Ninomiya.

UNIVERSIDADE DE SÃO PAULO

FACULDADE DE DIREITO

São Paulo-SP

2018 
Fujita, Danilo Yoshiaki

CONCORRÊNCIA DESLEAL NO DIREITO JAPONÊS : LIÇŐES

PARA O BRASIL / Danilo Yoshiaki Fujita ; orientador Masato Ninomiya - Săo Paulo, 2018

123

Dissertação (Mestrado - Programa de Pós-Graduação em Direito Internacional) - Faculdade de Direito, Universidade de São Paulo, 2018.

1. Direito Internacional. 2. Propriedade Intelectual. 3. Livre Concorrência. 4. Concorrência Desleal. I. Ninomiya, Masato, orient. II. Título. 
A Banca Examinadora, abaixo assinada, aprova a Dissertação

\title{
A CONCORRÊNCIA DESLEAL NO DIREITO JAPONÊS: LIÇÕES PARA O BRASIL
}

\author{
elaborada por \\ DANILO YOSHIAKI FUJITA \\ como requisito parcial para a obtenção do grau de \\ MESTRE EM DIREITO INTERNACIONAL \\ BANCA EXAMINADORA:
}

Prof. Dr. Masato Ninomiya, Orientador (FDUSP) 


\section{AGRADECIMENTOS}

Agradeço ao meu orientador Professor Masato Ninomiya por compartilhar seus conhecimentos acadêmicos e, principalmente, pelas lições sobre o país que me fascina pela organização, segurança, gastronomia e honestidade - o Japão.

Aos meus tios Maria Ligaya Fujita e Edmundo Fujita (in memoriam), quem realmente me introduziu o mundo acadêmico e me incentivou, apresentando-me o meu orientador Masato Ninomiya.

Aos advogados japoneses Junichi Matsuda, Yoshinobu Mizutani, Junichi Shirai, Tatsuhiro Kubo, Naoyuki Kenjo, Yasuyuki Nagai e demais membros do escritório Matsuda\&Partners, pela experiência única de trabalhar em um escritório japonês, vivenciar a cultura jurídica e conhecer o sistema jurídico, assim como por toda ajuda proporcionada durante minha estada.

Aos tradutores Shiho Tanaka, Andressa Iwai e Tatsuro Suzuki pela indispensável tradução dos textos acadêmicos em japonês para português.

Aos meus pais biológicos, Roberto Fujita e Yukiko Kashiwaya; e meus pais de criação, Mitiê Urayama e Roberto Kashiwaya pela minha formação.

À minha amada esposa Tatiane Fujita e meus filhos Eduardo Fujita e Christian Fujita pela compreensão e paciência. Somente quem convive diuturnamente com um estudante sabe das renúncias familiares.

Aos meus amigos Hissao Arita, Marcelo Barbosa, Leandro Moreira, Mirtes Shiraishi, Isabel Nishime, Luiz Phelipe, Jardel Gonçalves, Vinicius Moraes, Patrícia Anastácio, Mariana Lima e Erico Oliveira e a todos membros da Advocacia Masato Ninomiya por compartilharem seus conhecimentos.

Aos exemplos acadêmicos Edson Sadao Ilzuka, minha irmã Tatiana Fujita e Aurea Tanaka pelo constante apoio e incentivo.

Ao Grupo NK, meu atual empregador, na pessoa de Nelson Nakada e Ricardo Nakada pela compreensão durante minhas pesquisas. 
Aos Professores Maristela Basso e Carlos Augusto de Assis pelos conselhos no exame de qualificação.

À Universidade de São Paulo, Japan International Cooperation Agency (JICA), Kaigai Nikkeijin Kyokai (Associação dos Nikkeis no Exterior), Japan External Trade Organization (JETRO) pela acolhida e oportunidade da pesquisa. 
FUJITA, Danilo Yoshiaki. A Concorrência desleal no direito japonês: lições para o Brasil. 2018. 121 f. Dissertação (Mestrado em Direito Internacional) - Departamento de Direito Internacional da Faculdade de Direito da Universidade de São Paulo - USP. São Paulo, 2018.

\section{RESUMO}

Os interesses nacionais de recuperação econômica e tecnológica levaram o Japão a adotar medidas de proteção aos direitos de propriedade intelectual, a partir de 1868. A proteção desses direitos era indispensável para que o Japão conquistasse a confiança da comunidade internacional e consequentemente fomentasse a economia nacional. Este particular interesse obrigou o Japão a adotar formalmente o padrão mínimo de repressão às práticas desleais previstas na CUP. Todavia, a economia japonesa ainda não havia atingido grau de desenvolvimento suficiente para efetivamente implantar a proteção sem causar restrições ao mercado. Somente após ter atingido nível satisfatório de desenvolvimento econômico e tecnológico, pressionado pelo mercado interno e pela comunidade internacional, o Japão inicia efetivamente a regular a concorrência leal entre as empresas. $\mathrm{O}$ ambiente adequado de incentivo aos investimentos em inovações somente seria possível pela correta regulação aos interesses empresariais com segurança jurídica. Em nome dessa segurança jurídica, optou-se pelo estabelecimento de rol taxativo de atos proibidos e posteriormente a criação de um "Tribunal Superior de Propriedade Intelectual". Esse trabalho objetivou delinear o tratamento básico conferido pela lei de repressão à concorrência desleal Japonesa.

Palavras-chave: Direito Internacional. Propriedade Intelectual. Concorrência Desleal. Livre Concorrência. 
FUJITA, Danilo Yoshiaki. The Unfair Competition in Japanese Law: Lessons for Brazil. 2018. 121 f. Dissertation (Masters in International Law) - Department of International Law at the Law School of the University of São Paulo - USP. São Paulo, 2018.

\begin{abstract}
The national Japanese interests into recovery the economy and tecnology, leads it to adopt measures to protect Intelectual Property Rights since 1868. The protection was essential to Japan gain its confidence in front of International community and consequently develop its own National Economy. This particular interest obligated Japan to adopt the standard of protection of unfair competition set forth in CUP. However, the Japanese economy would not be achieved enough development to apply protection without causing restrictions for the market. Only after have reached satisfied level of technology and economy development, Japan effectively started to regulate the fair competition between enterprises, pushed by internal market and international comunity. The appropriate environmental of an incentive of investments on innovation would be possible by properly regulated with legal certainty. In name of legal certainty, Japan sets forth an exhaustive list of prohibited acts and further established the "Intellectual Property High Court". Therefore, this work aimed at the definition of the basic concept of Japanese Repression of Unfair Competition Act.
\end{abstract}

Keywords: International Law. Intellectual Property. Unfair Competition. Free Competition. 


\section{SUMÁRIO}

\section{INTRODUÇÃO}

1 A REPRESSÃO À CONCORRÊNCIA DESLEAL

1.1 REFERÊNCIAS NO DIREITO INTERNACIONAL

1.1.1 Convenção da União de Paris 13

1.1.2 Acordo de Madrid 16

$\begin{array}{ll}\text { 1.1.3 TRIPS } & 17\end{array}$

1.1.4 OMPI 18

1.1.5 Outros países 19

1.2 A REPRESSÃO À CONCORRÊNCIA DESLEAL NO JAPÃO 20

1.2.1 Perspectiva histórica 20

1.2.1.1 Ocupação das Forças Aliadas 24

1.2.1.2 Proteção a conquistas comerciais 24

1.3 QUADRO RESUMO DAS ALTERAÇÕES 27

1.4 OBJETIVO DA LEI 30

1.5 PRINCIPAIS CARACTERÍSTICAS 31

1.6 ROL DOS ATOS PROIBIDOS 32

1.7 CONSIDERAÇÕES SOBRE O SISTEMA DE REPREENSÃO 33

1.7.1 Leis de propriedade intelectual 34

1.7.2 Concorrência desleal e o direito patentário 34

1.7.3 Concorrência desleal e a Lei de Marcas 35

1.7.4 Concorrência desleal e a Lei antitruste 36

1.7.5 Concorrência desleal e o Código Comercial 37

1.7.6 Concorrência desleal e o Código Civil 38

\section{DOS ATOS PROIBIDOS}

2.1 APROPRIAÇÃO POR CONFUSÃO 39

2.1.1 Introdução 39

2.1.2 Disposição legal $\quad 40$

2.1.3 Requisito da Notoriedade $\quad 41$

2.1.3.1 Área geográfica comum 41

2.1.3.2 Quem é o consumidor descrito na lei? 42

2.1.3.3 O que é notoriedade? 43

2.1.4 Requisitos da Confusão 44

2.1.4.1 Conceito Clássico 44

2.1.4.2 Confusão de indicações de produtos 45

2.1.4.3 Confusão de indicações de estabelecimento empresarial $\quad 47$

2.1.4.4 Confusão por associação ao grupo econômico 48

2.1.5 Proteção das marcas notoriamente conhecidas 49

2.1.5.1 Similaridade entre as leis de marca e concorrência desleal 51

2.2 APROPRIAÇÃO DE INDICAÇÕES FAMOSAS 52

2.2.1 Proteção às marcas famosas no Japão 55

2.3 APROPRIAÇÃO POR IMITAÇÃO ("DEAD COPIES") 56

2.3.1 Requisitos $\quad 58$

2.3.1.1 Produtos 58

2.3.1.2 Configuração do produto $\quad 59$

2.3.1.3 Configuração de uso comum dos produtos 60

2.3.1.4 Período de 3 anos, contados da primeira venda 61 
2.3.1.5 Adquirente de boa-fé $\quad 62$

2.3.2 Proteção pelas leis de propriedade intelectual 62

2.4 APROPRIAÇÃO DE SEGREDOS EMPRESARIAIS 63

2.4.1 Definição, requisitos e formas 64

2.4.1.1 Aquisição, uso ou divulgação direta ou originária 65

2.4.1.2 Aquisição, uso ou divulgação indireta ou derivada 66

2.4.1.3 Proibição superveniente de uso ou divulgação 67

2.4.1.4 Uso ou divulgação mercenária ou predatória 68

2.4.1.5 Aquisição mercenária ou predatória 69

2.4.1.6 Produção de bens a partir do segredo empresarial impropriamente adquirido

69

2.4.1.7 Boa-fé na aquisição como exceção à deslealdade 69

2.4.2 Cláusulas contratuais restritivas $\quad 70$

2.5 APROPRIAÇÃO OU USO INDEVIDO DE NOME DE DOMÍNIO 72

2.5.1 Regulação perante a Lei de Concorrência Desleal Japonesa 74

2.6 APROPRIAÇÃO PELO AGENTE OU REPRESENTANTE 76

2.6.1 Apropriação por abuso de confiança $\quad 77$

2.6.2 Marcas estrangeiras notórias registradas pelos nacionais $\quad 78$

2.7 DEPRECIAÇÃO AOS NEGÓCIOS ALHEIOS 80

$\begin{array}{ll}2.7 .1 \text { Introdução } & 80\end{array}$

2.7.2 Desenvolvimento Internacional $\quad 81$

2.7.3 Atos prejudiciais à reputação dos negócios alheios 82

2.7.3.1 Ações baseadas no Código Civil 83

$\begin{array}{ll}\text { 2.7.3.2 Propagandas comparativas } & 84\end{array}$

2.7.4 Invalidação de medidas tecnológicas restritivas 86

$\begin{array}{ll}2.8 \text { INDICAÇÕ̃ES ENGANOSAS } & 89\end{array}$

2.8.1 Direito Internacional 90

2.8.2 Indicações enganosas na LRCD 90

2.8.3 Bandeiras, brasões, emblemas de países estrangeiros e organizações internacionais 92

2.8.4 Promessa, oferta ou concessão de vantagem indevida 92

2.9 EXCEÇÕES ÀS APLICAÇÕES 93

3 APLICABILIDADE DA LEI DE REPRESSÃO À CONCORRÊNCIA DESLEAL

3.1 CULTURA JAPONESA COMO PRECEDENTE NORMATIVO

3.1 CULTURA JAPONESA COMO PRECEDENTE NORMATIVO 97

3.2 TRIBUNAL SUPERIOR DE PROPRIEDADE INTELECTUAL 97

$\begin{array}{ll}\text { 3.3 REMÉDIOS LEGAIS } & 102\end{array}$

3.3.1 Liminares para abstenção do ato desleal 102

$\begin{array}{ll}\text { 3.3.2 Destruição dos produtos } & 104\end{array}$

3.3.3 Indenização por perdas e danos 105

$\begin{array}{ll}\text { 3.3.4 Pedido de desculpas } & 108\end{array}$

3.4 SEGREDO DE JUSTIÇA 108

$\begin{array}{ll}3.5 \text { SANÇÕES CRIMINAIS } & 110\end{array}$

$\begin{array}{ll}\text { CONCLUSÃO } & 111\end{array}$

$\begin{array}{ll}\text { REFERÊNCIAS } & 117\end{array}$ 


\section{INTRODUÇÃO}

A crescente globalização dos mercados provocou mudanças complexas nos padrões de comércio e investimento internacional que exigem uma nova estrutura de análise ${ }^{1}$. O Japão passou de um país em desenvolvimento para um país desenvolvido ${ }^{2}$ e se destacou

[...] no período do segundo-pós-guerra, por seu desempenho econômico e seus grandes avanços na área da ciência e tecnologia, particularmente, a partir da segunda metade da década de 1980. Suas realizações nessas áreas colocaram-no em uma posição de destaque internacional. $\mathrm{O}$ sucesso obtido fazia com que outros países, governos, empresas e estudiosos encontrassem no Japão modelos a serem, senão copiados, tidos como padrão de referência. Exemplos disso são fornecidos pela popularização de marcas como Sony, Cassio, Toyota e de alguns sistemas de administração como Just-in-time e kanban ${ }^{3}$.

Tais fatores impulsionaram os questionamentos sobre o papel e a participação do Japão nas relações internacionais, incluindo a adequada proteção internacional da propriedade intelectual.

A lei de repressão à concorrência desleal se torna uma importante ferramenta nesse contexto, uma vez que ao regulamentar os interesses empresariais e demonstrar $\circ$ cumprimento das obrigações internacionais assumidas nos tratados contribui com o desenvolvimento da economia nacional.

Este trabalho tem como objetivos descrever a evolução da lei de repressão à concorrência desleal japonesa desde seu nascimento, quando se mostrava limitada diante das demandas do mercado nacional e internacional até a versão atual. A limitação inicial pode ser atribuída, em grande parte, pela combinação de dois fatores: opção legislativa de se adotar um rol exaustivo de atos proibitivos e pela falta de vontade política na aplicação do texto existente, esse último em virtude da fase inicial de desenvolvimento de mercado. Pressionado pela comunidade internacional e após ter atingido alto grau de desenvolvimento tecnológico, o Japão

\footnotetext{
${ }^{1}$ NAKANO, Yoshiaki. Globalização, competitividade e novas regras de comércio mundial. Revista de Economia Política. v. 14, n. 4 (56), 1994.

2

<http://www.un.org/en/development/desa/policy/wesp/wesp_current/2014wesp_country_classificati on.pdf>

3 UEHARA, Alexandre Ratsuo. A política externa do Japão no final do século xx. O que faltou? São Paulo: Annablume, 2003, p. 12.
} 
passou a cumprir efetivamente a proteção contra concorrência desleal. $O$ cumprimento se deu pelo constante aperfeiçoamento da legislação demandada pela jurisprudência e pelos tratados internacionais. Desde sua promulgação até a versão atual (2015), a lei de repressão à concorrência desleal foi alterada mais de 20 vezes.

Fatores como a cultura jurídica da população, o nível de detalhamento dos atos proibitivos, regras que facilitaram o ônus da prova em favor do autor, a criação de um tribunal especializado para tratar de assuntos relacionados à propriedade intelectual podem ser destacados como fatores impulsionaram a adequada repressão à concorrência desleal. Nesse contexto, com maiores reflexões, emergem possíveis contribuições para o direito brasileiro.

Assim, ao expor os problemas e as soluções encontradas no sistema jurídico japonês seria possível refletir melhor sobre os problemas comuns e a possibilidade de se adaptar às soluções de sucesso ao contexto brasileiro. Ademais, possíveis interessados na legislação japonesa como investidores, profissionais do governo, pesquisadores, dirigentes de empresas etc. terão a oportunidade de avaliar o conteúdo da lei de repressão à concorrência desleal japonesa.

Este trabalho está dividido em 2 capítulos. O primeiro traz o cenário internacional de onde o Japão se inspirou, seu desenvolvimento nacional e as práticas desleais. O segundo capítulo descreve a aplicação da lei dentro do sistema jurídico. Finalmente, a conclusão. 


\section{CONCLUSÃO}

O presente trabalho buscou apresentar o tratamento conferido pela atual lei de repressão à concorrência japonesa, que contou com mais de 20 alterações legislativas desde seu nascedouro, em 1934, até o último registro em 2015. A partir dessa observação, destacaram-se alguns fatores que, conforme análise da literatura acadêmica, podem ser considerados como experiência bem-sucedida. Para que se possa tratar da relevância da pesquisa, apresentam-se os principais resultados alcançados ao longo dessa investigação.

Os mais importantes movimentos no sentido da proteção aos direitos de propriedade intelectual no Japão, da qual a repressão à concorrência desleal faz parte, coincidem com períodos em que o Japão necessitava recuperar a confiança internacional para superar períodos de recessão econômica, dentre os quais podem ser destacados:

A Era Meiji (1868-1912) constituiu uma importante fase de formação da consciência jurídica sobre a proteção da propriedade intelectual como fator de desenvolvimento econômico, culminando na adesão do Japão à Convenção de Paris em 1900.

Período pós-Primeira Guerra Mundial em que os países unionistas preocupados com as consequências econômicas da Guerra, firmam o compromisso na Revisão de Haia (1925) de adotar medidas efetivas contra práticas desleais, que levou a promulgação da primeira Lei de Repressão à Concorrência Desleal em 1934.

Período pós-Segunda Guerra Mundial, ainda durante a ocupação das forças aliadas, como medida de recuperação da economia, o Japão reforça a proteção aos interesses empresariais ao aderir ao Acordo de Madrid contra supressão de indicações de procedência e facilita os requisitos para obtenção de liminares para abstenção de atos desleais.

Período pós-Guerra Fria, apesar de colocar o Japão em posição de destaque na liderança internacional, as expectativas não se concretizaram devido ao estouro 
da bolha econômica em 1991253. A LRCD foi completamente reformulada para elevar a proteção consideradas limitadas pelos precedentes e adequações preparatórios para harmonização da Lei Modelo da OMPI. A Lei recebe nova numeração (Lei $n^{\circ} 47$ de 17 de maio de 1993). Outras reformas foram realizadas para adequação do Acordo TRIP's (1994) e para inclusão de medidas de combate à corrupção (1998). Ainda sob os reflexos da recessão do estouro bolha econômica, como tentativa de recuperação da economia, em 2005, foi criado o Tribunal Superior de Propriedade Intelectual com objetivo de dar maior segurança jurídica com decisões mais especializadas, céleres e uniformes sobre propriedade intelectual.

A proteção à concorrência desleal inicia timidamente pela interpretação ampliativa concedida pela Suprema Corte Imperial (1925) com precedente "Daigaku-yu”. A Suprema Corte Imperial reverteu a decisão da instância inferior e reconheceu como ato ilícito (art. 709 do Código Civil) a apropriação de indicação de título de estabelecimento "Daigaku-yu", sem registro e sem autorização do titular. Até então, a jurisprudência japonesa, influenciada pelo artigo 823 do BGB, entendia que o ressarcimento só seria possível se demonstrado a violação à um direito absoluto. A partir desse precedente foi ampliada a interpretação de "direito absoluto" para quaisquer interesses legais de modo que passou a ser possível a aplicação do Código Civil para proteção de práticas desleais, até que a lei específica entrasse em vigor em 1934.

O Japão optou por regular os interesses privados empresariais pela lei específica com adoção de um rol taxativo de atos proibidos. Ao adotar o rol taxativo, o Japão assegurou aos empresários claramente quais eram os limites éticos das práticas empresariais, deixando menos espaço para jurisprudência construir os referidos limites. Essa opção garantiu ao Governo o maior controle da regulação segundo as diretrizes dos interesses nacionais alinhado com a meta de recuperação econômica e tecnológica.

De um lado, o Japão precisava ganhar confiança internacional para recuperar sua economia, de outro, o mercado ainda não tinha amadurecido

\footnotetext{
253 UEHARA, Alexandre Ratsuo. A política externa do Japão no final do século xx. O que faltou? Ed. Annablume, p. 209.
} 
suficientemente para efetiva implantação das proibições sem que afetasse o desenvolvimento tecnológico e econômico. Esse conflito levou o Japão a promulgar a primeira LRCD (1934), contendo apenas a previsão de 4 (quatro) atos, mas sem efetiva aplicação devido a dificuldade imposta à parte lesada de se comprovar a má-fé do infrator.

A proteção foi gradativamente elevada em 1950 e 1965, até que em 1993, já com nível de desenvolvimento industrial satisfatório e pressionado pelo mercado interno pelas limitações da lei anterior, realiza-se uma revisão completa da Lei, que recebe nova numeração (Lei n47/1993). Essa revisão também foi pressionada pelos países membros do GATT, dada possibilidade da conclusão da Rodada do Uruguai.

Outra importante causa das alterações deve ser atribuída às novas possibilidades de praticar atos desleais com a chegada da tecnologia. Nesse sentido, passaram a ser considerados desleais atos de apropriação ou uso indevido de nome de domínio, qualquer tipo de transação com dispositivos dotados de função capaz de obstruir o efeito de medidas de restrição e atos praticados a partir de transações on-line.

Atualmente a LRCD permanece com estipulação de um rol taxativo de atos. Essa opção, juntamente com as demais leis que compõe o sistema de proteção à concorrência desleal e o sistema judiciário, não impediu que o Japão construísse um ambiente favorável às atividades inventivas. Por isso, subsiste o interesse em sua análise como experiência.

Essas foram as constatações levantadas pela pesquisa na atual legislação em vigor. Passemos para apresentação dos possíveis exemplos na experiência japonesa, conteúdo do segundo objetivo do trabalho.

O processo legislativo em sentido amplo pode ser apontado como possível diferencial na eficiência legislativa. A temática concorrência desleal, assim como leis de propriedade industrial, ficam sob a competência do Ministério da Economia, Indústria e Comércio (METI) que possui um papel importantíssimo na definição das políticas econômicas nacionais e detém competência para iniciativa de projetos de lei. A concentração dessas competências facilitou as alterações na medida em que 
o mercado exigia maior regulação. O constante aperfeiçoamento legislativo foi realizado de acordo com as necessidades particulares do mercado japonês.

Não obstante o Japão ter adotado o sistema de direito positivo, a jurisprudência dos Tribunais Superiores exerce forte influência sobre os casos a serem postos em juízo. Com intuito de oferecer maior segurança jurídica sobre matérias de propriedade intelectual, um Tribunal Superior de Propriedade Intelectual foi criado em 2005. Apesar de não ser elegível pela competência das varas distritais especializadas de Tóquio e Osaka, assuntos relacionados à concorrência desleal serão tratados pelo Tribunal Superior de PI em sua competência recursal se a ação for proposta em uma das varas distritais do Distrito de Tóquio. Uma estatística publicada da Suprema Corte indica que o assunto "concorrência desleal" figura como segundo tema mais acessado de propriedade intelectual em primeira instância e o terceiro mais demandado em segunda instância. Devido à sua natureza especial inter-relacionada com todas as outras matérias de propriedade intelectual, entende-se como adequada que seu tratamento seja pela competência exclusiva das Varas Distritais especializadas, a fim de se alcançar a desejada segurança jurídica.

A adequada proteção às práticas desleais envolveu também reformas nos procedimentos para decretação de segredo de justiça em processos que envolvem informações sigilosas como patentes e segredo empresarial. Dentre as medidas, podem ser destacadas procedimento preliminar para avaliação da necessidade de se apresentar ou não as informações, restrição ao acesso das informações às pessoas específicas, realização de audiências de portas fechadas. A elevação das multas pecuniárias por violação às práticas leais de concorrência mostra-se eficiente no combate à concorrência desleal.

Não se pode negar que a adoção do rol exaustivo, conjugado com a criação de um tribunal especial cuja competência abrange o principal distrito de Tóquio, confere maior segurança jurídica no que se refere a aplicação da LRCD. Os precedentes criados por este Tribunal Especializado tendem a servir de referência aos demais órgãos julgadores, especialmente em razão da forte hierarquia presente na cultura japonesa pode trazer um efeito indireto na observação dos precedentes. 
Após apresentar os principais pontos que foram tratados nessa dissertação, torna-se possível citar as duas principais contribuições, as quais sintetizam a relevância da investigação empreendida:

Não se encontrou outro trabalho no Brasil a respeito da lei japonesa de repressão à concorrência desleal de modo que esta pesquisa poderá abrir as discussões entre os interessados brasileiros, em especial os empresários e operadores do direito que eventualmente tenham interesse na compreensão do tema que impacta diretamente nas transações comerciais e investimentos internacionais.

A estatística apresentada pela Suprema Corte Japonesa em 2015 demonstra que a matéria da concorrência desleal é segunda classe de ações em maior número em primeira instância, representando 22,9\% do total de processos existentes. Em segunda instância, fica em $3^{\circ}$ lugar com 11,8\%. Ou seja, a tendência é de um mercado cada vez mais competitivo e, portanto, em que o processo concorrencial tende a se ampliar e se tornar ainda mais complexo. Diante desse contexto, a lei de repressão à concorrência desleal ganha maior representatividade e evidência.

No tocante à aplicação dos resultados, duas propostas podem ser mencionadas. Uma delas é a acadêmica. Ao se organizar a literatura sobre a lei de repressão à concorrência desleal em língua portuguesa, abre-se um caminho para que outros pesquisadores possam se dedicar a tal temática. A outra implicação é de ordem aplicada (ou prática), pois os profissionais do Direito poderão usufruir das informações apresentadas, seja das questões relacionadas à jurisprudência, exemplos bem-sucedidos, posicionamento da suprema corte japonesa entre outros.

A pesquisa ficou limitada a análise dos textos e da jurisprudência. Ademais, a reflexão sobre as práticas exitosas no Japão no contexto brasileiro merece maior atenção dada à diversidade cultural, mercadológica e cultura jurídica, dentre outros. Assim, a presente pesquisa trouxe a primeira narrativa sobre a experiência japonesa, mas que merece um debate mais aprofundado. 
A lei de concorrência desleal japonesa é apenas uma das leis que integram o sistema de proteção à concorrência. Uma das opções para futuras pesquisas, dentre as várias possíveis neste campo, poderia levar em conta uma análise sistemática a partir de uma visão integrada da Lei Antitruste ou uma visão sistematizada de todas as leis que compõem o sistema de repressão à concorrência desleal. Outro ponto aparentemente interessante seria investigar se o Japão estaria apto para adotar uma cláusula geral. O Brasil nesse quesito adota um sistema misto contemplando um rol taxativo e uma cláusula aberta.

A adequada regulação da concorrência tem como pressuposto 0 aperfeiçoamento, o avanço, a melhoria. Quanto mais agressiva for a competição, mas leal, melhores serão os frutos para sociedade. Contudo, o acirramento da competição entre agentes econômicos propicia o surgimento de práticas desonestas, haja vista necessidade de se encontrar vantagens competitivas. $\mathrm{O}$ estudo deste tema ganha cada vez mais importância em razão da internacionalização das transações comerciais. A troca de experiências entre os países revela-se essencial na busca da adequada regulação. 


\section{REFERÊNCIAS}

ANDERMAN, Steven. The Interface Between Intellectual Property Rights and Competition Policy.

ASCARELLI, Tullio. A atividade do empresário. Tradução de Erasmo Valladão A. e N. França. Revista de Direito Mercantil, n. 132, p. 203 e 212.

ASCARELLI, Tullio. Teoria da la concurrencia y de los bienes inmateriales. Barcelona: Bosch. 1970.

ANDERMAN, Steven. The interface between Intellectual Property Rights and Competition Policy. Cambridge. 2007

AZEVEDO, Álvaro Villaça. O novo Código Civil Brasileiro: tramitação; função social do contrato; boa-fé objetiva; teoria da imprevisão e, em especial, onerosidade excessiva (laesio enormis). Revista Jurídica n. 308, jun. 2003.

AZEVEDO, Antônio Junqueira de. O princípio da boa-fé nos contratos.

Comentários sobre o Projeto do Código Civil Brasileiro. Série Cadernos do CEJ, 20. Acesso em: <http://www.cjf.gov.br/> set. 2003.

BARBOSA, Dênis B. Uma introdução à propriedade intelectual. Rio de Janeiro: Lúmen Juris, 2010.

. Da tecnologia à cultura. Rio de Janeiro: Lúmen Juris, 2011.

Juris, 2003.

Direito Internacional da Propriedade Intelectual. Rio de Janeiro: Lúmen

Da proteção do trade dress com ou sem direitos exclusivos. Parecer sobre confusão ou associação entre as marcas ou trade dress dos produtos LINOLEIC X LINOLEN. Rio de Janeiro, 2009.

BARBOSA, Dênis Borges. Uma introdução à propriedade intelectual. Rio de Janeiro: Lúmen Júris, 2003. p. 13; FREITAS, Sílvia Rodrigues de. Comparative study of legislation and examination practices concerning trademarks in Brazil and Japan. Tóquio, 2010.

BASSO, Maristela. O Direito Internacional da Propriedade Intelectual. Porto Alegre: Livraria do Advogado, 2000.

. Propriedade Intelectual e Importação Paralela. São Paulo: Atlas, 2011.

. Desenho industrial e Trade Dress após o caso Apple $x$ Samsung.

<www.migalhas.com.br> Publicado 19 out. 2012. 
BRENT T. Yonehara, A Review of Japan's Protection of Domain Names against Cybersquatting, 43 IDEA 207 (2003)

BULGARELLI, Waldirio. Direito Comercial. São Paulo: Atlas, 2001.

DUNNEY, Edward G. New Trade Secrets Law, IP ASIA, 1990.

GREENBERG, Suzanne F. The WIPO Model Laws for the Protection of Unpatented Know-How: a comparative analysis.

HAHN, Eliiott. An overview of Japanese Legal System. 5 Nw. J. Int'l L. \& Bus. 517 (1984)

HEATH, Christopher. The System of Unfair Competition Prevention in Japan. Max Planck Series on Asian Intellectual Property Law. Kluwer Law International, 2005.

HENNING-BODEWIG, Frauke. International Handbook on Unfair Competition. Oxford: Hart Publishing, 2013

; Chapter 17: IP-based nation: Strategy of Japan. Emerging Markets and the World Patent Order. European Intellectual Property Institutes Network series. 2013.

JAPANESE FAIR TRADE COMMISSION - JFTC - Designation of Unfair Trade Practices. 1982. <http://www.jftc.go.jp/en/legislation_gls/unfairtradepractices.html> . Specific Unfair Trade Practices in Newspaper Business. 1999.

<http://www.jftc.go.jp/en/legislation_gls/index.files/spaper.pdf>

. Designation of Specific Unfair Trade Practices by Large-Scale Retailers Relating to the Trade with Suppliers. 2005.

<http://www.jftc.go.jp/en/legislation_gls/index.files/dsutp.pdf>

Keizaisangōshō Chiteki Zaisan Seisaku (Ministério da Economia, Comércio e Indústria do Japão (METI). Chikujō kaisetsu Fusei kyōsō bōshi-hō (Lei de concorrência desleal cláusula por cláusula). Tóquio, 2015.

LADAS, Stephen. Patents, Trademarks and Related Rights. Cambridge: Harvard University Press, 1975

LAFER, Celso. A OMC e a regulamentação do comércio internacional: uma visão brasileira. Porto Alegre: Livraria do Advogado, 1998.

LaFRANCE, Mary. Passing off and unfair competition: conflict and convergence in competition law, 2011.

LEMLEY, Mark A., William H. Neukom Property, Intellectual Property and Free Riding. 2005. Texas Law Review. 
LIMA, Mariana de Araújo Mendes. A proteção das marcas renomadas no Brasil e no Japão. Dissertação de Mestrado. São Paulo: Universidade de São Paulo, 2016.

MASAYOSHI, Tsunoda. Hanrei Tsuki Chiteki Zaisan Ken Roppou. Compêndio de leis de propriedade intelectual e a jurisprudência. Japão, Sanseido, 2017.

MIRANDA, Pontes. Tratado de Direito Privado, § 2095. Classificação dos atos ilícitos de concorrência.

MORO, Maitê Cecília Fabri. A marca tridimensional, sua proteção e os aparentes conflitos com a proteção outorgada com outros institutos da propriedade intelectual. Tese de Doutorado em Direito defendida pela PUC/SP, 2005, p. 51.

NINOMIYA, Masato; TANAKA, Aurea; Uehara, Alexandre; FUJITA, Edmundo; Horisaka, Kotaro. 120: Construindo os Alicerces para o Futuro das Relações Brasil-Japão. São Paulo, Ed. Lexia, 2016.

NINOMIYA, Masato; TANAKA, Aurea. Desafios geopolíticos da Ásia no século XXI: Japão, China e Coreia. Revista Política Externa. v. 24, 2015.

NINOMIYA, Masato. Mutual legal assistance in criminal matters between Brazil and Japan. University of Tokyo, Journal of Law and Politics, v. 4, p. 65-76, 2007.

. Glossary of Juridical Terms Portuguese-Japanese, co-author with Seiichi Mori, Yuhikaku, Tokyo, 2000.

. YATANI, Michiro. Burajiru Kogy EShoyuuken H E (Nova Lei de Propriedade Industrial) versão para a língua japonesa da Lei n. 9.279, de 14 de maio de 1996, com breve comentário. São Paulo: Kaleidos-Primus Consultoria e Comunicação Integrada S/C Ltda., 1996. 210p . Intercâmbio Cultural Brasil-Japão - Sistema Jurídico Japonês.

NAKAYOSHI, Hideo. New Japanese Trade Secrets Act, Trademark World, November 1992

ONISHI, Hiroko. Well-known trade marks: a comparative study of Japan and the EU. Oxon: Routeldge, 2015

ONO, Syouen. Fusei kyōsō bōshi hō gaisutsu. A Lei de repressão à concorrência desleal. Ed. Shinichi Himumi, 2015.

PALMER, Vernon; BUSSANI, Mauro. Pure Economic Loss. New horizons in Comparative Law. (Chapter 2. NOMI, Yoshida. Japan). Routledge Cavendish. 2009.

POLIDO, Fabrício Bertini Pasquot. Direito Internacional da Propriedade Intelectual: fundamentos, princípios e desafios. Rio de Janeiro: Renovar, 2013. 
PORT, Kenneth L. Trademark and Unfair Competition Law and Policy in Japan. Durham: Carolina Academic Press, 2007.

RAHN, Guntram. The Role of Industrial Property in Economic Development: The Japanese Experience, 1983.

RIFFEL, Christian. Protection Against Unfair Competition in the Wto trips agreement. The scope and prospects of Article 10bis of the Paris Convention for the Protection Intellectual Property

RODRIGUES JR.; BEAS, Edson Beas; POLIDO, Fabrício. Propriedade intelectual, novos paradigmas internacionais, conflitos e desafios. São Paulo: Campus, 2007.

ROHL, Wilhelm. History of Law in Japan since 1868.

SILVEIRA, Newton. Propriedade intelectual. Barueri, SP: Manole, 2011. Júris, 2008.

. Estudos e pareceres de propriedade industrial. Rio de Janeiro: Lúmen . Licença de uso de marca e outros sinais distintivos. São Paulo: Saraiva, 1984.

Direito de autor no design. São Paulo: Saraiva, 2012.

SHINOHARA, Katsumi. Outline of the Intellectual Property High Court of Japan. AIPPI 2005.

STEENSTRUP, C. A history of Law in Japan until 1868, 1996.

SCHMIDT-SZALEWSKI, Joanna Schmidt. The international protection of trade marks after the trips agreement. Duke Journal of Comparative \& International. v. 8:189, p. 192.

KINSELLA, Stephan. Contra a propriedade intelectual. Tradução de Rafael Hotz. São Paulo: Instituto Ludwig vonMises Brasil, 2010.

TAMURA, Yoshiyuki. Chapter 9: Protection of the first mover advantage:

Regulation against imitation of the product configuration in Japan. Intellectual Property, Unfair Competition and Publicity. Convergences and Development. European Intellectual Property Institutes Network series. 2014.

WISE, A. Trade secrets and know-how throughout the world. v. 1, ch. 1 (1981); Amemiya \& Guttman, Know-How, in doing business in Japan, v. 4, pt. VI, ch. 5 (Z. Kitagawa ed. 1984).

WORD INTELLECTUAL PROPERTY ORGANIZATION. WIPO. The Enforcement of Intellectual Property Rights: A case book. Genebra, 2012 LTC Harms 
YAMAMURA, Kozo; SAXONHOUSE, Gary. Law and Trade Issues of the Japanese Economy. American and Japanese Perspectives. 1986, p. 163.

\section{Sites Consultados}

AIPPI. International Association for Protection of Intellectual Property Right in Japan. Disponível em: www.aippi.org. Acesso em: 10 jul. 2017;

INPI. Instituto Nacional da Propriedade Industrial. Convenção de Paris. Disponível em: http://www.inpi.gov.br/legislacao-1/cup.pdf. Acesso em: 26 dez. 2017.

JAPANESE LAW TRANSLATION. Disponível em:

http://www.japaneselawtranslation.go.jp/. Acesso em: 12 jan. 2017

JFC. Japan Fair Trade Commission: https://www.jftc.go.jp/ Acesso em 05 jul. 2017

JPO. Japan Patent Office: <https://www.jpo.go.jp/> Acesso em: 26 out. 2017

LIBRARY OF CONGRESS. Global legal monitor. Japan: Streaming and Transfer of Recorded TV Programs Services Abroad Found Illegal. Disponível em:

http://www.loc.gov/lawweb/servlet/loc news?disp3 1205402508 text. Acesso em: 12 fev. 2017.

MAX PLANCK INSTITUTE FOR INNOVATION AND COMPETITION. Disponível em: <http://www.ip.mpg.de> Acesso em: 30 out. 2017

MINISTÉRIO DA ECONOMIA, COMÉRCIO E INDÚSTRIA (METI). Disponível em http://www.meti.go.jp Acesso em 24 nov. 2017

MINISTÉRIO DAS RELAÇÕES EXTERIORES E COMUNICAÇÃO: Disponível em: http://www.stat.go.jp/english/index.htm Acesso em 10 dez. 2017

ORGANIZAÇÃO MUNDIAL DO COMÉRCIO. Acordo sobre Aspectos dos Direitos de Propriedade Intelectual Relacionados ao Comércio. Disponível em:

http://www.desenvolvimento.gov.br/arquivos/dwnl 1196686160.doc. Acesso em: 26 dez. 2017.

SUPREMA CORTE DO JAPÃO. Disponível em http://www.courts.go.jp/ Acesso em 03 jan. 2018

TRADEMARKS. Disponível em: http://www.wipo.int/trademarks/en/trademarks.html. Acesso em: 11 jan. 2017.

WIPO. World Intellectual Property Organization.. Acesso em: 26 dez. 2017 